\title{
Effect of steaming on the functional compounds and antioxidant activity of Fijian taro (Colocasia esculenta L. Schott) corms
}

\author{
Yeon Soo Kim ${ }^{1}$, Damilare Adeyemi ${ }^{1}$, Ponijese Korovulavula ${ }^{1}$, Dong Wook Jang ${ }^{1}$, \\ Mi-Kyung Park ${ }^{1,2 *}$ \\ ${ }^{1}$ School of Food Science and Biotechnology, Kyungpook National University, Daegu 41566, Korea \\ ${ }^{2}$ Food and Bio-Industry Research Institute, Kyungpook National University, Daegu 41566, Korea
}

\begin{abstract}
We investigated the effects of steaming Fijian taro (Colocasia esculenta L. Schott) corms on their functional compound contents and antioxidant activities by comparison with those of un-steamed Fijian taro corms. Taro corms from Fiji were washed, peeled, cut, then either steamed or left un-steamed, and freeze-dried. Ten gram of each freeze-dried taro corm sample was extracted with water, methanol, and ethanol. The total phenolic content (TPC) and total flavonoid content (TFC) of the taro corms were determined using the Folin-Ciocalteu's colorimetric and the aluminum chloride colorimetric methods, respectively. The antioxidant activity was determined using the 2,2-diphenyl1-picrylhydrazyl (DPPH) radical scavenging activity, ferric reducing antioxidant power (FRAP), and 2,2'-azino-bis (3-ethylbenzothiazoline-6-sulfonic acid) (ABTS) radical scavenging activity. The water-extracted steamed Fijian taro corm showed the greatest extraction yield of $11.58 \pm 1.20 \%$, whereas the ethanol-extracted un-steamed Fijian taro corm exhibited the lowest extraction yield of $4.24 \pm 0.77 \%$. The TPC $(42.77 \pm 3.39 \mathrm{mg}$ gallic acid equivalents/g dry weight) and TFC (12.68 $\pm 4.85 \mathrm{mg}$ catechin equivalents/g dry weight) of the methanol-extracted steamed Fijian taro corms were significantly larger than those of the other extracts $(\mathbf{p}<0.05)$. The steamed Fijian taro corms extracted with methanol significantly demonstrated greatest activities in DPPH radical scavenging activity (34.82 $\pm 2.91 \%)$, FRAP (339.08 $\pm 20.50 \mathrm{mM}$ Trolox equivalents), and ABTS radical scavenging activity $(56.34 \pm 3.54 \%)(\mathrm{p}<0.05)$. This study provides the basis for developing a healthy snack food based on steamed Fijian taro.
\end{abstract}

Key words : Fijian taro corm (Colocasia esculenta L. Schott), steaming, functional compounds, antioxidant activity

\section{Introduction}

Taro (Colocasia esculenta L. Schott), a starchy tuber crop belonging to the Araceae family, is one of the most widely grown crops in the tropical and sub-tropical areas of the world $(1,2)$. There are several different taro species including Alocasia macrorrhizos (giant taro), C. esculenta (true or ordinary taro), Cyrtosperma chamissonis (giant swamp taro), and Xanthosoma sagittifolium (tannia). Among them, the true taro (C. esculenta) is the most important species for agriculture and human consumption (3). The large

*Corresponding author. E-mail : parkmik@knu.ac.kr Phone : 82-53-950-5776, Fax : 82-53-950-6772

Received 05 November 2018; Revised 27 December 2018; Accepted 28 December 2018.

Copyright (c) The Korean Society of Food Preservation. All rights reserved. underground corms of taro are especially one of the most popularly consumed staple foods in Asia, Africa, the Caribbean, Middle and South America and the Pacific Islands $(2,4)$. In Fiji, taro is an important staple food and cash crop for Fijian communities (5).

The taro corm is a rich source of carbohydrates and fibers as well as small starch granules that play an essential part in its digestibility and the enhanced bioavailability of nutrients (6). In addition, taro corms are good sources of phosphorus, zinc, potassium, iron, magnesium, calcium, vitamins, flavonoids, carotenoids, and phenolic compounds, which play important roles in reducing the risk of cancer, cataracts, cardiovascular diseases, and gall bladder and inflammatory bowel diseases (6-8). In addition, the corms contain functional compounds including phenolic and flavonoid compounds such as cyanidin, delphinidin, isorhamnetin, kaempferol, myricetin, quercetin, chlorogenic acid, and p-coumaric acid 
(9). Baiao et al. reported (9) that quercetin is the major phenolic and flavonoid compound found in taro corm. These compounds provide several benefits such as antioxidant, antiallergic, anti-inflammatory, antibacterial activities, and reducing risk of type-2 diabetes (9).

Previous research using taro corms has focused on the identification of its nutritional compositions and health benefits $(7,10)$. In addition, Kaushal et al. (7) reported the effects of extraction conditions (solvent types and processing methods) on the production of taro-based products. Melese and Negussie (6) found that the heat treatment of taro corms, such as steaming and boiling, reduces the anti-nutrients in taro corms such as oxalic acid, mucilage, tannins, cyanide, and protease inhibitors. In addition, Chumyam et al. (11) reported the effects of steaming on the antioxidant activities of vegetables. Although steaming provides beneficiary aspects in food processing and consumption to prevent browning and reduce anti-nutrients, there is still room for controversy on whether the steaming of taro corms enhance the functional compounds and antioxidant activity. In addition, no studies have been conducted to identify the effect of steaming on functional compounds (total phenolic content (TPC) and total flavonoid content (TFC) and antioxidant activity of Fiji taro corm. The goal of our research is to develop healthy taro snacks with Fijian taro corms. Thus, as a first step, the functional compounds and antioxidant activity of steamed Fijian taro corms were compared with those of un-steamed Fijian taro corms.

\section{Materials and methods}

\section{Extraction of Fiji taro corms using solvents}

Fijian taro ( $C$. esculenta L. Schott) corms were provided by the Sigatoka Research Station (Nacocolevu, Fiji), and stored in a well-ventilated room at $4{ }^{\circ} \mathrm{C}$ with $85 \% \mathrm{RH}$ before use. After the Fijian taro corms had been washed and peeled, the peeled corms were cut into 0.5 -cm-thick slices using a stainless-steel knife, placed into a pot with a sieve, and steamed for $10 \mathrm{~min}$. Alternatively Fijian taro corms were cut into small pieces without any exposure to heat. After the Fijian taro corms had been freeze-dried, $10 \mathrm{~g}$ of each freeze-dried steamed or un-steamed sample was mixed with $200 \mathrm{~mL}$ of filtered distilled water (FDW), 80\% methanol, or $80 \%$ ethanol, The corms and solvent were then agitated at $180 \mathrm{rpm}$ agitation for $48 \mathrm{~h}$ at room temperature. For the extract yields, the mixture was filtered with filter paper
(Whatman Inc., Maidstone, Kent, UK) and evaporated by rotary evaporation (IKA Works Inc., Staufen, Germany). The extract yields for each solvent were calculated by subtracting the dried weight of the Fijian taro corm residues after extraction from the weight of the freeze-dried Fijian taro corm. The Fijian taro corm extracts were stored at $4^{\circ} \mathrm{C}$ until further use.

\section{Determination of total phenolic content (TPC)}

TPC was determined by the Folin-Ciocalteu's colorimetric method, and gallic acid $(0,2.5,5,10$, and $20 \mathrm{mg}$ gallic acid equivalents/g) was used as a standard solution (12). An aliquot of $0.2 \mathrm{~mL}$ of each Fijian taro corm extract was mixed with $1.8 \mathrm{~mL}$ of FDW and $0.2 \mathrm{~mL}$ of Folin-Ciocalteu reagent and vortexed. After $6 \mathrm{~min}, 2 \mathrm{~mL}$ of $7 \%$ sodium carbonate solution (Daejung Chemicals \& Metals Co., Siheung, Korea) was added to each mixture, which was then incubated for $90 \mathrm{~min}$. The absorbance of the mixture was measured at $750 \mathrm{~nm}$ using a spectrophotometer (Mecasys Co., Daejeon, Korea). The average absorbance values obtained at different concentrations of gallic acid were used to plot the calibration curve. The TPC is expressed as milligrams gallic acid equivalents (mg GAE/g- freeze-dried Fijian taro corm sample).

$T P C$ content $(m g G A E / g)=$ Std.value $(\mathrm{mg} / \mathrm{mL}) \times \frac{\text { Totalvol.of extract }(\mathrm{mL}) \times \text { dilution factor }}{\text { Sample }(\mathrm{g})}$

Determination of total flavonoid content (TFC)

TFC was determined using the aluminium chloride colorimetric method (13) with minor modifications. An aliquot of $0.5 \mathrm{~mL}$ Fijian taro extract was mixed with $2 \mathrm{~mL}$ of FDW and $150 \mu \mathrm{L}$ of $5 \%$ sodium nitrite $\left(\mathrm{NaNO}_{2}\right.$, Daejung Chemicals \& Metals Co.). After $5 \mathrm{~min}, 150 \mu \mathrm{L}$ of $10 \%$ aluminium chloride $\left(\mathrm{AlCl}_{3}\right.$, Daejung Chemicals \& Metals Co., Siheung-si, Korea) was added and the reaction mixture was incubated for $1 \mathrm{~min}$ at room temperature. After adding 1 $\mathrm{mL}$ of $1 \mathrm{~N}$ sodium hydroxide, the absorbance of the mixture was measured at $510 \mathrm{~nm}$. Catechin at concentrations of 0 , $2.5,5,10$, and $20 \mathrm{mg}$ catechin equivalents (CE)/g was used as a standard solution. The average absorbance values obtained at different concentrations of catechin were used to plot the calibration curve. The results are expressed as milligram catechin equivalents (mg $\mathrm{CE} / \mathrm{g}$ freeze-dried Fijian taro corm sample).

TFCcontent $(m g C E / g)=S t d$. value $(m g / m L) \times \frac{\text { Totalvol.of extract }(m L) \times \text { dilution factor }}{\text { Sample }(g)}$ 


\section{Determination of DPPH radical scavenging activity}

The 2,2-diphenyl-1-picrylhydrazyl (DPPH)-free radical scavenging activities of the Fijian taro corm extracts were determined using Blois's method (14) with minor modifications. An aliquot of $2 \mu \mathrm{L}$ of the Fijian taro corm extract was added to a $198 \mu \mathrm{L}$ methanolic solution of DPPH radicals (50 $\mu \mathrm{M} \mathrm{DPPH})$ and left to stand in the dark for $10 \mathrm{~min}$ at room temperature. Then, the absorbance was measured at $517 \mathrm{~nm}$. The DPPH content is expressed as the percentage inhibition.

$$
\text { DPPHradical scavengingactivity }(\%)=\frac{\text { Control } O D-\text { Sample } O D}{\text { Control } O D} \times 100
$$

\section{Determination of FRAP activity}

The ferric reducing antioxidant power (FRAP) activity of the sample extract was determined following the method of Benzie and Strain (15) with minor modifications. A FRAP solution was prepared by mixing $50 \mathrm{~mL}$ of $0.3 \mathrm{M}$ acetate buffer ( $3.1 \mathrm{~g}$ sodium acetate $\left(\mathrm{C}_{2} \mathrm{H}_{3} \mathrm{NaO}_{2}\right)$ and $16 \mathrm{~mL}$ acetic acid $\left.\left(\mathrm{C}_{2} \mathrm{H}_{4} \mathrm{O}_{2}\right), \quad \mathrm{pH} 3.6\right), 5 \mathrm{~mL}$ of $10 \mathrm{mM} 2,2,6-$ tripyridyl-s-triazine (TPTZ) solution in $40 \mathrm{mM} \mathrm{HCl}$, and 5 $\mathrm{mL}$ of $20 \mathrm{mM} \mathrm{FeCl} 3 \cdot 6 \mathrm{H}_{2} \mathrm{O}$ solution, and the mixture was warmed to $37^{\circ} \mathrm{C}$ before use. An aliquot of $25 \mu \mathrm{L}$ of each Fijian taro corm extract was mixed with $175 \mu \mathrm{L}$ of FRAP reagent and left in the dark at room temperature for $30 \mathrm{~min}$. Trolox (Sigma-Aldrich Co., St. Louis, MO, USA) was used as a standard solution, and the average absorbance values obtained at different concentrations of Trolox $(0,12.5,25$, 50 , and $100 \mathrm{mM}$ ) were used to plot the calibration curve. The absorbance of the mixture was measured at $590 \mathrm{~nm}$ and the results are expressed as $\mathrm{mM}$ Trolox equivalent (mM TE).

\section{Determination of ABTS radical scavenging activity}

The 2,2'-azino-bis(3-ethylbenzothiazoline-6-sulfonic acid) (ABTS) assay was carried out according to the method described by Thaipong et al. (16). The ABTS radical cation (ABTS $^{+}$) solution was prepared by mixing the two stock solutions $\left(7.4 \mathrm{mM} \mathrm{ABTS}{ }^{+}\right.$solution and $2.6 \mathrm{mM}$ potassium persulfate solution) in equal quantities and left to react for $12 \mathrm{~h}$ at room temperature in the dark. The solution was then diluted by mixing $\mathrm{ABTS}^{+}$solution with ethanol to obtain an absorbance of $0.70 \pm 0.02$ units at $595 \mathrm{~nm}$ using the spectrophotometer. An aliquot of $25 \mu \mathrm{L}$ of each Fijian taro corm extract was allowed to react with $195 \mu \mathrm{L}$ of the ABTS $^{+}$ solution for $20 \mathrm{~min}$ in the dark condition and the absorbance was measured at $517 \mathrm{~nm}$. The ABTS content is expressed as the percentage inhibition.

ABTSradicalscavengingactivity $(\%)=\frac{\text { Control } O D-\text { Sample } O D}{\text { Control } O D} \times 100$

\section{Statistical analysis}

All experiments were performed in triplicate and the data were expressed as mean \pm standard deviation (SD). The data analysis was performed using the GraphPad Instat 3 (GraphPad Software Inc., San Diego, California, USA). The comparison between the groups was performed using a Student's t-test and one-way analysis of variance (ANOVA) and differences were considered statistically significant at $\mathrm{p}<0.05$.

\section{Results and discussion}

\section{Yields of Fijian taro corm extracts}

Because the polarity of the solvent could affect the taro corm extraction yields, three different solvents were used, and the percentage yield of each taro corm extract is presented in Fig. 1. As reported by Goli et al. (17), the extraction yield is dependent on the polarity of the solvent, as well as the extraction method, and the yields of steamed taro corms were greater than those of the un-steamed taro corms for all extractions. Further, as the polarity of the solvent increased (water > methanol > ethanol), the yields also increased. The steamed taro corm treated by aqueous extraction showed the greatest yield of $11.58 \pm 1.20 \%$. In contrast, the un-steamed taro corm treated by ethanol extraction had the lowest yield of $4.24 \pm 0.77 \%$.

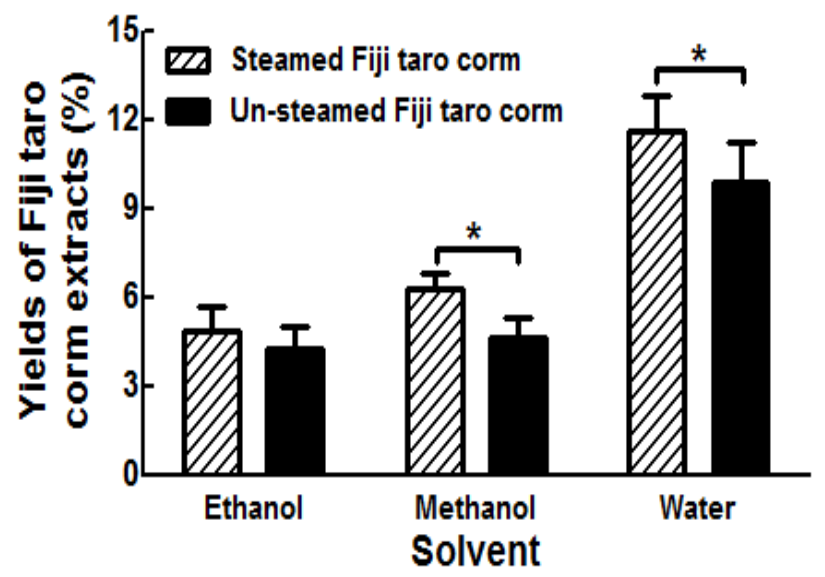

Fig. 1. Yields of steamed and un-steamed Fiji taro corm by using different solvent.

*Means is significantly different $(\mathrm{p}<0.05)$ by student's $t$ test. 
Statistically, the yields of steamed Fijian taro corm were significantly higher than those of un-steamed Fijian taro corm after methanol and ethanol extraction $(\mathrm{p}<0.05)$. The better yields of steamed taro corm over those of un-steamed taro corm in all extractions may be attributed to the hydrolysis of starch and softening effect of the steaming process, which result in the greater extraction of functional compounds and other nutrient compounds $(7,18)$.

Total phenolic content (TPC) and total flavonoid content (TFC) of Fiji taro corm extracts

The TPCs and TFCs of steamed and un-steamed Fijian taro corm extracts are expressed in terms of gallic acid equivalents (linear regression: $y=0.0512 x+0.0634, r^{2}=0.99$ ) and catechin equivalents (linear regression: $\mathrm{y}=$ $0.0379 \mathrm{x}+0.0366, \mathrm{r}^{2}=0.99$ ), respectively. As shown in Table 1, the steamed Fijian taro corms exhibited significantly greater TPCs than the un-steamed Fijian taro corms after both ethanol and methanol extraction $(\mathrm{p}<0.05)$. However, there were no significant differences in the TPCs of the ethanol and methanol extracts for both the steamed and un-steamed taro corms, although the methanol extract of steamed Fijian taro corm showed the greatest TPC $(42.77 \pm 3.39 \mathrm{mg} \mathrm{GAE} / \mathrm{g}$ dry weight). In contrast, there were no significant differences observed in the TFCs after the extraction of the steamed and un-steamed taro corms with ethanol and methanol, although the methanol extract of steamed Fijian taro corm showed the greatest TPC $(42.77 \pm 3.39 \mathrm{mg}$ GAE/g dry weight). In addition, the TPC and TFC of the aqeous extract were significantly lower than those of the ethanol and methanol extracts, and no significant effects of steaming were observed $(\mathrm{p}<0.05)$. Overall, the steaming process increased the TPC after extraction with methanol and ethanol, whereas there was no significant change in the TFC when using water

Table 1. Total phenolic content (TPC) and total flavonoid content (TFC) of Fiji taro corm extracts

\begin{tabular}{|c|c|c|c|}
\hline Sample & Solvent & $\begin{array}{c}\mathrm{TPC} \\
\left(\mathrm{mg} \mathrm{GAE}^{1} / \mathrm{g} \text { dry weight }\right.\end{array}$ & $\begin{array}{c}\text { TFC } \\
\text { (mg CE/g dry weight) }\end{array}$ \\
\hline \multirow{3}{*}{$\begin{array}{l}\text { Steamed } \\
\text { Fiji taro corm } \\
\text { extracts }\end{array}$} & Ethanol & $36.56 \pm 3.97^{\mathrm{ab} 2)}$ & $9.66 \pm 2.34^{a}$ \\
\hline & Methanol & $42.77 \pm 3.39^{\mathrm{a}}$ & $12.68 \pm 4.85^{\mathrm{a}}$ \\
\hline & Water & $13.97 \pm 2.28^{\mathrm{c}}$ & $4.32 \pm 2.12^{b}$ \\
\hline \multirow{3}{*}{$\begin{array}{l}\text { Un-steamed Fiji } \\
\text { taro corm extracts }\end{array}$} & Ethanol & $31.92 \pm 5.60^{b}$ & $10.24 \pm 3.51^{\mathrm{a}}$ \\
\hline & Methanol & $32.32 \pm 4.56^{b}$ & $10.34 \pm 3.32^{\mathrm{a}}$ \\
\hline & Water & $12.83 \pm 3.28^{c}$ & $4.53 \pm 2.25^{b}$ \\
\hline
\end{tabular}

${ }^{1)} \mathrm{GAE}$, gallic acid equivalent; $\mathrm{CE}$, catechin equivalent.

${ }^{2)}$ Values are mean $\pm \mathrm{SD}(\mathrm{n}=3)$. Values with different superscript $(\mathrm{a}, \mathrm{b}$, and $\mathrm{c})$ within the same column are significantly different $(\mathrm{p}<0.05)$. extraction. In addition, the TPC:TFC ratio is consistent with that reported by Smisek and El (2), which indicates that one-quarter of the taro TPC was TFC.

The TPC and TFC vary with extraction method and conditions, as well as the region of taro cultivation (climatic variations and soil conditions) (2). For example, the TPCs of Turkish (2), Japanese (19), Singaporean (20), and Fijian taro corms (21) were determined to be $187 \pm 53,46,180$, and $12-39 \mathrm{mg} \mathrm{GAE} / 100 \mathrm{~g}$ dry weight, respectively. With respect to the work of Jeon et al. (22), our TPC values (31.92-42.77 mg GAE/g dry weight) were greater than their TPC values obtained using aged black taro corms (20.61-28.20 mg GAE/g dry weight), even when using un-steamed taro corms. Overall, the TPCs of the Fijian taro corms were greater than those reported in previous studies, and steaming increased the TPCs in both the ethanol and methanol extracts.

The effect of steaming vegetables on the TPC and TFC is dependent on the type of vegetable. For example, the TPCs of eggplant, spinach, sweet corn, and pepper increase after three heating processes (steaming, boiling, and micro-waving) (11), but the TPCs of tomatoes, garlic, pungent peppers, and fresh-cut broccoli decrease, presumably because of the reduction of antioxidant capacity (11). The final goal of our project is to develop a healthy taro-based snack using steamed taro; thus, the positive effect of steaming on the TPC and corresponding increase in antioxidant activity (because TPC rather than TFC is associated with antioxidant activity) $(11,18)$ is very promising.

\section{Antioxidant activity of Fijian taro corm extracts}

The antioxidant activity of Fijian taro corm extracts were determined on the basis of the DPPH radical scavenging activity, FRAP activity, and ABTS radical scavenging activity (Table 2). In regards to the DPPH radical scavenging activity, the steamed Fijian taro corm extracted with methanol and ethanol exhibited excellent DPPH radical scavenging activities of $34.82 \pm 2.91 \%$ and $27.23 \pm 2.58 \%$, respectively, which are significantly greater than those of the other treatments $(\mathrm{p}<0.05)$. Meanwhile, the DPPH radical scavenging activities of un-steamed Fijian taro corms were lower than those of steamed Fijian taro corms in all extracts. Our results are consistent with those of Saikia and Mahanta (23). In their study, the DPPH radical scavenging activities of banana blossom, cauliflower, beet root, green pea, tomato, and carrot were increased after steaming and ranged from $10.30 \pm 0.16 \%$ for green peas to $92.89 \pm 0.21 \%$ for banana blossom.

The FRAP results of steamed and un-steamed Fijian taro 
corm extracts are expressed in terms of Trolox equivalents (linear regression: $\mathrm{y}=0.002 \mathrm{x}+0.1249, \mathrm{r}^{2}=0.98$ ). The trend in FRAP activity is similar to that of DPPH activity; that is, the methanol-extracted steamed Fijian taro corm ( $339.08 \pm 20.50 \mathrm{mM}$ TE) exhibited the greatest FRAP activity of all samples $(\mathrm{p}<0.05)$; in contrast, there was no significant difference in the FRAP activities observed between the water extracts of the steamed and un-steamed Fijian taro corm. In addition, the FRAP activity of the ethanol and methanol extracts of steamed and un-steamed Fijian taro corms were significantly greater than those of the aqueous extracts $(\mathrm{p}<0.05)$.

In regards to the ABTS activity, steamed Fijian taro corm extracted with methanol exhibited the greatest ABTS activity $(56.34 \pm 3.54 \%)(\mathrm{p}<0.05)$, followed by the ethanol-extracted steamed taro corm $(46.86 \pm 2.38 \%)$. Furthermore, steamed Fijian taro corm showed better ABTS activity than the un-steamed Fijian taro corm. The resulting pattern of ABTS activity was similar to the DPPH radical scavenging activity results, which is consistent with the results of other studies $(22,24,25)$ in that a greater ABTS activity led to an increase in DPPH activity.

Our results agree with those of previous studies $(2,11,18)$ that have shown that antioxidant activity is mainly correlated with the TPC containing TFC. Moreover, most studies have found that DPPH and ABTS activities correlate with the TPC. We found that the steaming of Fijian taro corms resulted in softening, so the TPC and TFC extraction was increased, which led to an increase in the extraction of functional components and enhanced the total antioxidant activity. Thus, the positive effect of steaming on the TPC and antioxidant activity of Fijian taro corms will provide benefits for developing a healthy snack based on Fijian taro.

Table 2. Antioxidant activity of steamed and un-steamed Fiji taro corm extracts

\begin{tabular}{|c|c|c|c|c|}
\hline Sample & Solvent & $\begin{array}{l}\mathrm{DPPH}^{1)} \text { radical } \\
\text { scavenging } \\
\text { activity }(\%)\end{array}$ & $\begin{array}{c}\text { FRAP radical } \\
\text { scavenging activity } \\
\text { (mM TE) }\end{array}$ & $\begin{array}{c}\text { ABTS radical } \\
\text { scavenging activity } \\
(\%)\end{array}$ \\
\hline \multirow{3}{*}{$\begin{array}{c}\text { Steamed } \\
\text { Fiji taro } \\
\text { corm extracts }\end{array}$} & Etl & $27.23 \pm 2.58^{\mathrm{b} 2)}$ & $260.32 \pm 16.57^{b}$ & $46.86 \pm 2.38^{b}$ \\
\hline & Methanol & $34.82 \pm 2.91^{\mathrm{a}}$ & $339.08 \pm 20.50^{\mathrm{a}}$ & $56.34 \pm 3.54^{\mathrm{a}}$ \\
\hline & Water & $14.12 \pm 3.13^{\mathrm{d}}$ & $153.51 \pm 14.92^{\mathrm{cd}}$ & $23.36 \pm 0.16^{\mathrm{d}}$ \\
\hline \multirow{3}{*}{$\begin{array}{l}\text { Un-steamed } \\
\text { Fiji taro } \\
\text { corm extracts }\end{array}$} & Ethanol & $18.09 \pm 1.40^{\text {cd }}$ & $179.41 \pm 10.81^{c}$ & $37.89 \pm 0.87^{\mathrm{c}}$ \\
\hline & Methanol & $24.37 \pm 4.23^{\mathrm{bc}}$ & $224.72 \pm 13.24^{b}$ & $42.33 \pm 0.31^{b c}$ \\
\hline & Water & $13.12 \pm 3.42^{\mathrm{d}}$ & $115.57 \pm 12.11^{\mathrm{d}}$ & $18.10 \pm 1.78^{d}$ \\
\hline
\end{tabular}

${ }^{1)} \mathrm{DPPH}, 1,1$-diphenyl-1-picrylhydrazyl; FRAP, ferric ion reducing antioxidant power; ABTS, 2,2-azino-bis-3-ethylbenzthiazoline-6-sulphonic acid.

${ }^{2)}$ Values are mean $\pm S D(n=3)$. Values with different superscript (a, b, c, and d) within the same column are significantly different $(\mathrm{p}<0.05)$.

\section{Conclusion}

In this study, the effects of steaming Fijian taro corms on both their functional compound contents and antioxidant activities were investigated by comparison with un-steamed corms. The yield of the steamed Fijian taro corm extracted with water was the highest at $11.58 \%$, while that of the un-steamed Fijian taro corm extracted with ethanol was the lowest at $4.24 \%$. The TPC (42.77 mg GAE/g dry weight) and TFC (12.68 mg CE/g dry weight) of the steamed Fijian corms extracted with methanol were significantly greater than those of other extracts $(\mathrm{p}<0.05)$. In the same way, the methanol-extracted steamed Fijian taro corms exhibited significantly greatest activities in DPPH, FRAP, and ABTS $(\mathrm{p}<0.05)$. Hence, this study will contribute to the development of healthy functional snacks derived from steamed Fijian taro corms.

\section{References}

1. Rodriguez-Miranda J, Ruiz-Lope II, Herman-Lara E, Martinez-Sanchez CE, Delgado-Licon E, Vivar-Vera MA (2011) Development of extruded snacks using taro (Colocasia esculenta L. schott) and nixtamalized maize (Zea mays) flour blends. LWT-Food Sci Technol, 44, 673-680

2. Simsek S, El SN (2015) In-vitro starch digestibility, estimated glycemic index and antioxidant potential of taro (Colocasia esculenta) corm. Food Chem, 168, 257-261

3. Mergedus A, Kristl J, Ivancic A, Sober A, Sustar V, Krizan T, Lebot V (2015) Variation of mineral composition in different parts of taro (Colocasia esculenta) corms. Food Chem, 170, 37-46

4. Aboubakar Njintang YN, Scher J, Mbofung CMF (2008) Physicochemical, thermal properties and microstructure of six varieties of taro (Colocasia esculenta L.Schott) flours and starches. J Food Eng, 86, 294-305

5. Deo PC, Tyagi AP, Taylor M, Becker DK, Harding RM (2009) Improving taro (Colocasia esculenta var. esculenta) production using biotechnological approaches. South Pac J Nat Sci, 27, 6-13

6. Melese T, Negussie R (2015) Nutritional potential, health and food security benefits of taro colocasia esculenta (L.): A review. Food Sci Qual Manage, 36, 23-31

7. Kaushal P, Kumar V, Sharma HK (2015) Utilization of 
taro (Colocasia esculenta): a review. J Food Sci Technol, 52, 27-40

8. Yang Y, Achaerandio I, Pujola M (2016) Effect of the intensity of cooking methods on the nutritional and physical properties of potato tubers. Food Chem, 197, 1301-1310

9. Baiao DDS, de Freitas CS, Gomes LP, da Silva D, Correa ACN, Pereira PR, Aguila EMD, Paschoalin VMF (2017) Polyphenols from root, tubercles and grains cropped in Brazil: Chemical and nutritional characterization and their effects on human health and diseases. Nutrients, 9, 1044

10. Mbofung CMF, Aboubakar Njintang YN, Abdou Bouba A, Balaam F (2006) Physicochemical and functional properties of six varieties of taro (Colocasia esculenta L. schott) flour. J Food Technol, 4, 135-142

11. Chumyam A, Whangchai K, Jungklang J, Faiyue B, Saengnil K (2013) Effects of heat treatments on antioxidant activity and total phenolic content of four cultivars of purple skin eggplants. Sci Asia, 39, 246-251

12. Tawaha K, Alali FQ, Gharaibeh M, Mohammad M, El-Elimat T (2007) Antioxidant activity and total phenolic content of selected Jordanian plant species. Food Chem, 104, 1372-1378

13. Zhishen J, Mengcheng T, Jianming W (1999) The determination of flavonoid contents in mulberry and their scavenging effects on superoxide radicals. Food Chem, 64, 555-559

14. Blois MS (1958) Antioxidant determinations by the use of a stable free radical. Nature, 181, 1199-1200

15. Benzie IFF, Strain JJ (1996) The ferric reducing ability of plasma (FRAP) as a measure of "antioxidant power": The FRAP assay. Anal Biochem, 239, 70-76

16. Thaipong K, Boonprakob U, Crosby K, CisnerosZevallos L, Byrne DH (2006) Comparison of ABTS, DPPH, FRAP, and ORAC assays for estimating antioxidant activity from guava fruit extracts. J Food Compos Anal, 19, 669-675

17. Goli AH, Barzegar M, Sahari MA (2005) Antioxidant activity and total phenolic compounds of pistachio (Pistachia vera) hull extracts. Food Chem, 92, 521-525
18. Aboubakar Njintang YN, Scher J, Mbofung CMR (2009) Texture, microstructure and physicochemical characteristics of taro (Colocasia esculenta) as influenced by cooking conditions. J Food Eng, 91, 373-379

19. Takebayashi J, Oki T, Watanabe J, Yamasaki K, Chen J, Sato-Furukawa M, Tsubota-Utsugi M, Taku K, Goto $\mathrm{K}$, Matsumoto T, Ishimi Y (2013) Hydrophilic antioxidant capacities of vegetables and fruits commonly consumed in Japan and estimated average daily intake of hydrophilic antioxidants from these foods. J Food Compos Anal, 29, 25-31

20. Isabelle M, Lee BL, Lim MT, Koh WP, Huang D, Ong CN (2010) Antioxidant activity and profiles of common vegetables in Singapore. Food Chem, 120, 993-1003

21. Lako J, Trenerry VC, Wahlqvist M, Wattanapenpaiboon N, Sotheeswaran S, Premier R (2007) Phytochemical flavonols, carotenoids and the antioxidant properties of a wide selection of Fijian fruit, vegetables and other readily available foods. Food Chem, 101, 1727-1741

22. Jeon YH, Lee JW, Son YJ, Hwang IK (2016) Characteristics and sensory optimization of taro (Colocasia esculenta) under different aging conditions for food application of black taro. Korean J Food Sci Technol, 48, 133-141

23. Saikia S, Mahanta CL (2013) Effect of steaming, boiling and microwave cooking on the total phenolics, flavonoids and antioxidant properties of different vegetables of Assam, India. Int J Food Nutr Sci, 2, 47-53

24. Floegel A, Kim DO, Chung SJ, Koo SI, Chun OK (2011) Comparison of ABTS/DPPH assays to measure antioxidant capacity in popular antioxidant-rich US foods. J Food Compos Anal, 24, 1043-1048

25. Dudonne S, Vitrac X, Coutiere P, Woillez M, Merillon JM (2009) Comparative study of antioxidant properties and total phenolic content of 30 plant extracts of industrial interest using DPPH, ABTS, FRAP, SOD, and ORAC assays. J Agric Food Chem, 57, 1768-1774 